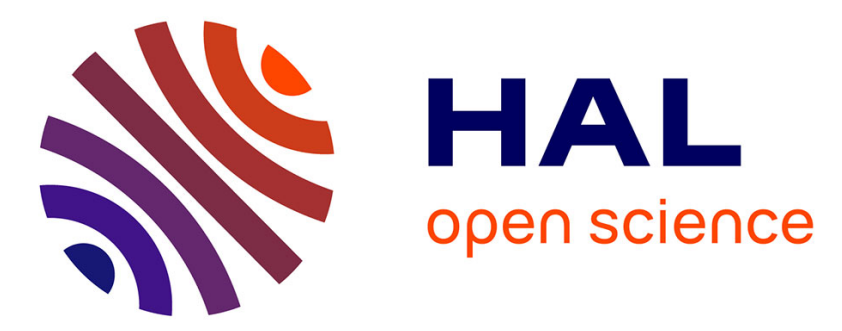

\title{
Shock-Wave Synthesis of Intermetallic Compounds Ti3Al, TiAl Analysis of Heterophase Structure Formation
}

E. Shorokhov, B. Greenberg, T. Boyarshinova, S. Sudareva, V. Buzanov, O. Antonova, E. Panova

\section{To cite this version:}

E. Shorokhov, B. Greenberg, T. Boyarshinova, S. Sudareva, V. Buzanov, et al.. Shock-Wave Synthesis of Intermetallic Compounds Ti3Al, TiAl Analysis of Heterophase Structure Formation. Journal de Physique IV Proceedings, 1997, 07 (C3), pp.C3-7-C3-12. 10.1051/jp4:1997304 • jpa-00255377

\section{HAL Id: jpa-00255377 https://hal.science/jpa-00255377}

Submitted on 1 Jan 1997

HAL is a multi-disciplinary open access archive for the deposit and dissemination of scientific research documents, whether they are published or not. The documents may come from teaching and research institutions in France or abroad, or from public or private research centers.
L'archive ouverte pluridisciplinaire HAL, est destinée au dépôt et à la diffusion de documents scientifiques de niveau recherche, publiés ou non, émanant des établissements d'enseignement et de recherche français ou étrangers, des laboratoires publics ou privés. 


\title{
Shock-Wave Synthesis of Intermetallic Compounds $\mathrm{Ti}_{3} \mathrm{Al}$, TiAl and Analysis of Heterophase Structure Formation
}

\author{
E.V. Shorokhov, B.A. Greenberg*, T.S. Boyarshinova*, S.V. Sudareva*, V.I. Buzanov, O.V. Antonova* \\ and E.V. Panova*
}

Russian Federal Nuclear Centre-VNITT, PB. 245, Chelyabinsk Region, Snezhinsk 456770, Russia

* Institute of Metal Physics, Ural Division, Russian Academy of Sciences, 18 S. Kovalevskoi str., Ekaterinburg, 620219 Russia

\begin{abstract}
The intermetallics have been synthesized from $\mathrm{Ti}_{3} \mathrm{Al}$ - and TiAl-composition powders by using the spherical shock waves and the structures was studied. The shock wave was formed by means of the spherical charge of explosive which surrounded a steel ball (capsule of conservation) with the powder mixture inside. It was revealed that the synthesized intermetallics had the increased microhardness as compared with materials obtained by traditional methods. The role of iron particles, injected during the synthesis from the capsule of conservation, in the formation of structure was found out. The existence of a great variety of phases, including metastable and nonequilibrium ones, was shown.

Résumé. Utilisant les ondes sphériques de choc le composé intermétallique à la base des poudres $\mathrm{Ti}_{3} \mathrm{Al}$ et $\mathrm{TiAl}_{\mathrm{A}}$ est synthétisé et l'analyse de la structure formée est effectué. L'onde de choc se forme à l'aide de l'explosif sphérique entourant la balle d'acier (capsule de conservation), au centre duquel le mélange pulvérulent est disposé. Il est décelé que le composé intermétallique synthétisé a la dureté accrue en comparaison des matériaux obtenus par les méthodes traditionnelles. Le rôle des particules de fer injectées pendant la synthése de la capsule de conservation est révelé pour la formation d'une structure. Il fait voir l'existence d'un grand nombre des phases, y compris celles métastables et non equilibrées.
\end{abstract}

\section{INTRODUCTION}

For the last time the main attention of investigators was drawn to the development of such methods of intermetallics synthesizing which can impart new qualities to these compounds. The usage of the shockwave compression, as a method of synthesis, opens the perspective direction for obtaining the intermetallics unusual properties. This method for the synthesis of materials provides for the shock-wave action on the appropriate powder, whereas the shock waves arise during the explosion of the charges located symmetrically over the surface of the shell - capsule of conservation in which the powder is found.

There are different methods for obtaining the intermetallics. However the method of the synthesis by means of the shock-wave action has a whole range of advantages. Firstly, it is the combination of high pressures and temperatures $[1,2]$. Secondly, for such kind of action on the substance the very small times of the dynamic load increase $\left(10^{-6}-10^{-7} \mathrm{~s}\right)$ and high rates of deformation are typical. The heterogeneous deformation and its distribution being extremely nonhomogeneous over the sample is the result of it. Besides a shock-wave action realizes very high rates of sample cooling (experimentally - to $10^{8}-10^{10} \mathrm{~K} / \mathrm{s}$ ). As a result the fast-quenched states arise with finely divided structure. Just in this direction the greatest improvement of the strength - and plastic characteristics of titanium aluminides should be expected.

$\mathrm{Up}$ to now the intermetallics $\mathrm{NiAl}, \mathrm{Ti}_{3} \mathrm{Al}$ and TiAl with higher hardness have been obtained by the shock-wave loading according to the cylindrical scheme for the stoichiometric mixtures of the nickel and aluminum powders as well as the titanium and aluminum ones [3].

The goal of the present investigation was synthesis of intermetallic compounds from the powders containing Ti-25 at.\% $\mathrm{Al}$ and Ti-50 at.\% Al by the shock-wave compression method: investigation into the obtained structure: analysis of reasons for increasing microhardness.

Article published online by EDP Sciences and available at http://dx.doi.org/10.1051/jp4:1997304 


\section{EXPERIMENTAL}

In the present work the quasispherical scheme of loading was used. For the synthesis the use was made of the titanium and aluminum powders of high purity with the size of particles $<63 \mu \mathrm{m}$ in the relation: 25 at.\% Al and 75 at.\% Ti for the first sample and 50 at.\% Al and 50 at.\% $\mathrm{Ti}$ for the second one. The powders were placed into the ball-wise capsule of conservation which was binary and consisted of two shells - the thick brass shell and the thin $(\approx 0,2 \mathrm{~mm})$ steel one directly adjoining to the sample. The loading was performed in 12 points, pressure amounted to $\approx 50 \mathrm{GPa}$ at the boundary of the porous medium with the steel shell.

The samples conserved after the experiment were of the form of the ball of approximately $15 \mathrm{~mm}$ in diameter, then they were cut into two equal halves, and investigations were performed. It appeared that the steel shell "was welded on" to the synthesized material. In the central part of the samples the cavity of the irregular form has formed (5-7 $\mathrm{mm}$ in diameter), its formation is the consequence of the energy cumulating in the sample center.

The phase composition and the structure of the obtained materials were studied by light microscopy (LM) in a NEOPHOT-20, by scanning electron microscopy (SEM) and microanalysis in a JSV-U3 and JCXA-733, by transmission electron microscopy (TEM) in JEM-2OOCX and by X-ray diffraction (in a DRON-3M using monochromatized $\mathrm{CuK}_{\alpha}$-radiation). Of all the mechanical properties only microhardness was measured.

\section{RESULTS AND DISCUSSION}

\subsection{Phase and structure study}

On the X-ray diffraction patterns of the sample synthesized from $\mathrm{Ti}_{3} \mathrm{Al}$-composition powder there are two systems of lines. One of them - relatively weak and broadening lines belonging to $\mathrm{CsCl}$ type ordered B2phase with the bulk-centered cubic (b.c.c.) lattice. Another system - strong and relatively narrow lines. Their interplanar spacings are very close to those of the fundamental lines of the ordered hexagonal $\alpha_{2}-$ phase $\left(\mathrm{Ti}_{3} \mathrm{Al}\right)$. However, the superlattice lines of this phase are absent in the diffraction patterns. According to all the available literary data $[4,5]$ it is impossible to obtain the phase of the $\mathrm{Ti}_{3} \mathrm{Al}$ composition in the disordered state by usual methods of quenching. However that permit us to assert that, as a result of the shock-wave compression of the powders, the nonequilibrium hexagonal phase of $\mathrm{Ti}_{3} \mathrm{Al}$ composition has been obtained which has been practically in the disordered state. These data agree, to a certain extent, with the results obtained during the rapidly solidification of the Ti-50 at.\% Al into thin foils of the intermetallic TiAl by the hammer-anvil quenching technique [6].

The X-ray diffraction of the sample synthesized from TiAl-composition powder shows three systems of lines. One system - narrow and strong lines - relates to $\mathrm{LI}_{0}$-type ordered $\gamma$-phase (TiAl). Another system of more weak lines is associated with the presence of the hexagonal phase being partially ordered. The third system of lines has not yet been identified. Co-existence of two phases of $\mathrm{TiAl}+\mathrm{Ti}_{3} \mathrm{Al}$ in the Ti-50 at.\% Al system obtained by the shock-wave compression was reported [3]. Moreover, the same phenomenon was observed during the rapidly solidification of the Ti-50 at. $\% \mathrm{Al}$ into thin foils by the hammer-anvil quenching technique [6]. LM revealed the dendritic structure of the Ti-50 at.\% Al sample (Fig. 1a) with dendrite sizes decreasing towards the spherical sample center. The presence of such structure gives evidence to the melting of the synthesized sample and its subsequent crystallization.

LM of the sample synthesized from $\mathrm{Ti}_{3} \mathrm{Al}$-composition powder showed the grains of oval and more elongated form which were stretched along the spherical sample radii (Fig. 1b). Near the steel chamber of conservation the more small equiaxial grains $30-50 \mu \mathrm{m}$ in size were observed. This reminded of the structure of the crystallized material although the grains have a more rounded form than it should be at the dendritic growth. According to the present conceptions [7] the dendritic structure formation during crystallization is possible in both samples, in Ti-25 at.\% $\mathrm{Al}$ as well as in Ti-50 at \% Al. For this the strong concentration supercooling of the melt is necessary. However, in the case of Ti-25 at.\% Al sample, 
at first $\beta$-phase of b.c.c. lattice is crystallized. Just at this time one should expect the formation of the sharp crystals - dendrites of the first order which are elongated along the radii and closely adjoining to each other. Then, under the further cooling the phase transformation from the $\beta$-phase into the disordered hexagonal phase of $\mathrm{Ti}_{3} \mathrm{Al}$ composition takes place which has a lamellar structure. As a result of this transformation, the phase recrystallization should take place. Therefore such structure appears which consist of the oval grains but conserves the elongation of the grains along the spherical sample radii, i.e. that elongation which arise during crystallization.

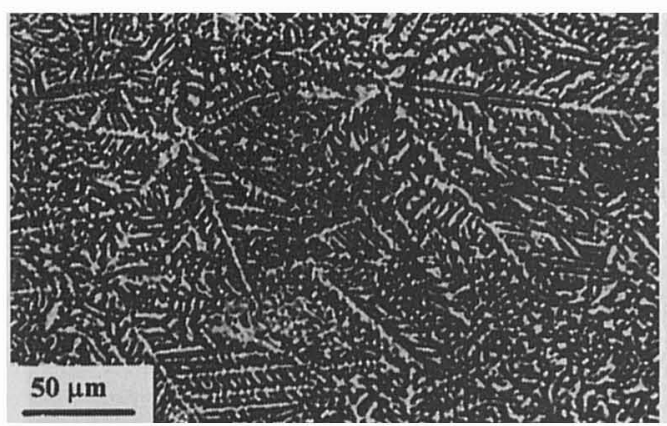

a)

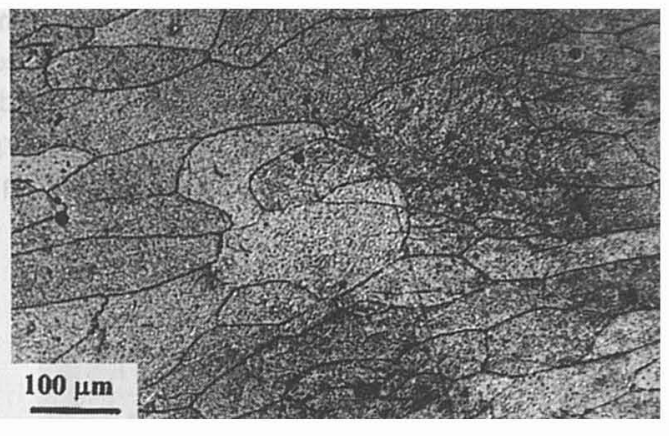

b)

Figure 1: Optical micrographs, showing the dendritic structure of the sample synthesized from the TiAl-composition powder (a) and grain one of the sample synthesised from the $\mathrm{Ti}_{3} \mathrm{Al}$-composition powder (b).

SEM investigation of the nonetched specimens from $\mathrm{Ti}_{3} \mathrm{Al}$ powder revealed no traces of dendritic liquation. The microanalysis with $\mathrm{Ti}, \mathrm{Al}, \mathrm{Fe}$ radiation showed that the specimen consists of $\mathrm{Ti}_{3} \mathrm{Al}$ phase with a small impurity of iron (1-2 at.\%) which does not form the marked atomic accumulations (aggregations). It has been also noted that iron concentration is slowly growing towards the specimen center and reaches its maximum - 2 at.\% near the central pore-cavity.

SEM observing in the secondary electrons of the etched samples from TiAl powder showed that the dendritic structure is clearly defined (Fig. 2a). SEM analysis of nonetched specimens revealed the wide boundaries between dendrites were distinctly revealed in the form of light regions (Fig. 2b). Apparently, this part of the crystal acts as the independent phase. Its quantity is increasing towards the sample center. The performed microanalysis with $\mathrm{Ti}$ and $\mathrm{Al}$ radiation has shown that the relative content of titanium and aluminum is, on the whole, identical inside dendrites and in their wide boundaries and fluctuates from some average value being, evidently, characteristic of the intermetallic compound TiAl towards the $\mathrm{Ti}_{3} \mathrm{Al}$ and $\mathrm{TiAl}_{3}$ phases.

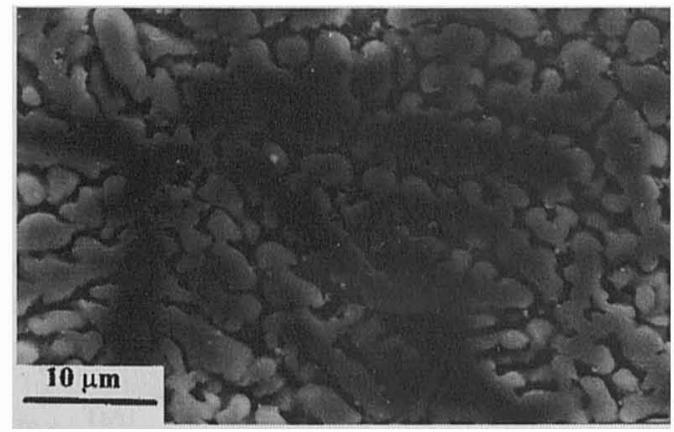

a)

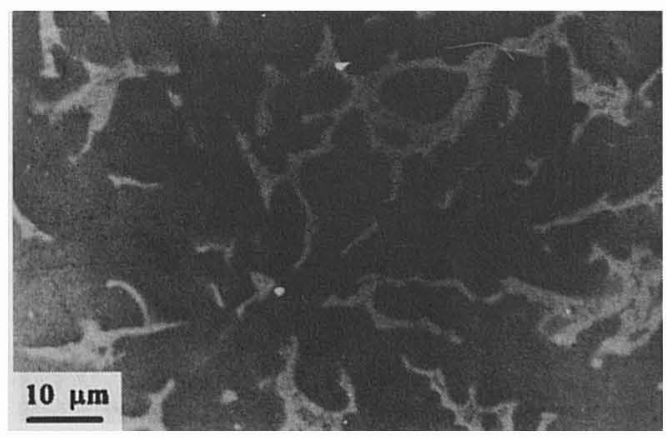

b)

Figure 2: SEM secondary electron micrographs of the dendritic structure of the sample synthesised from the TiAlcomposition powder etched prior to examination (a) and not etched (b). 
The microanalysis in Fe radiation revealed that the iron quantity was considerably greater in the TiAl sample than in the $\mathrm{Ti}_{3} \mathrm{Al}$ one, and the same tendency of its quantity rising towards the sample center was observed. It is possible that the increasing quantity of iron is the reason of the dendritic structure size reduction towards the sample center. Moreover it was noted that in dendritic crystals the iron content amounted to $1-3$ at.\% depending on the place of the analyzed section; along the dendrite boundaries its content amounted to 5-10 at.\%. In the last case it is possible to propose the occurrence of a new phase on the basis of $\mathrm{Ti}, \mathrm{Al}, \mathrm{Fe} \mathrm{[8]}$ and to relate it to the nonidentified system of the X-ray diffraction lines.

TEM study of the sample synthesized from $\mathrm{Ti}_{3} \mathrm{Al}$-composition powder showed the lameliar structure of the hexagonal phase with two characteristic dimensions of the plates (Fig. 3a). Thin plates form a "basket" structure. Inside the large plates the fine equiaxial domains, with the size $\sim 30 \mathrm{~nm}$, have been revealed. This corresponds to the early stages of ordering so far as the distinct superstructure reflections are seen in the microdiffractional pictures. In the large plates a well-developed substructure and separate dislocations were sometimes observed, some of them are blocked ones (Fig. 3b).

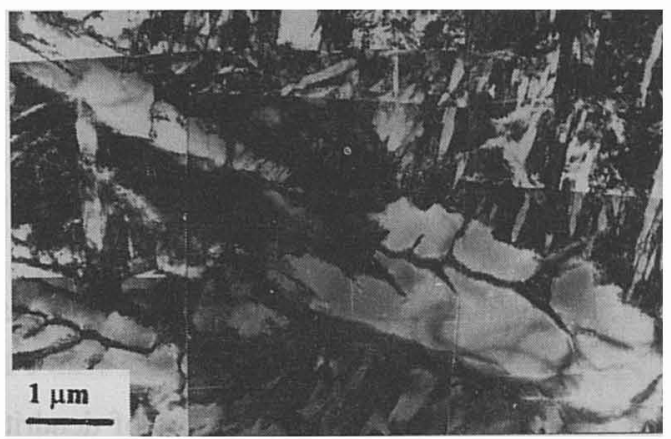

a)

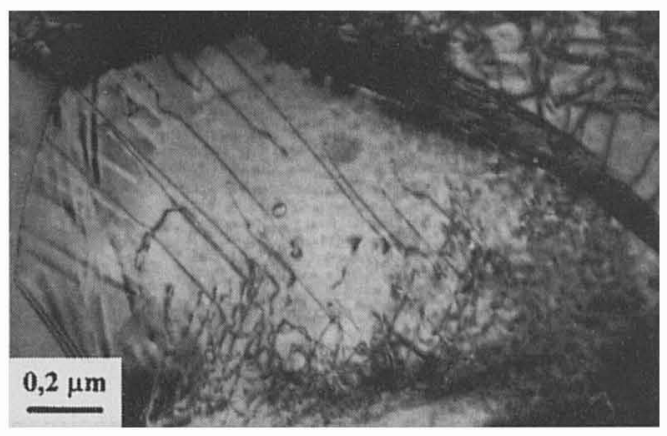

b)

Figure 3: TEM bright-field images of the hexagonal-phase lamellar structure (a) and of a blocked-dislocation structure in the sample synthesized from the $\mathrm{Ti}_{3} \mathrm{Al}$-composition powder (b).

TEM study of the sample synthesized from the TiAl-composition powder showed a great variety of structures. The metastable $\gamma$-phase with the low degree of a long-range order has the unusual structure: there are c-domains of 3 orientations within one and the same part of the sample and swirl-like antiphase domain structure (Fig. 4a). It has being supposed that $\gamma$-phase has heterogeneous structure, it is consists of the more ordered particles in the less ordered matrix.

The monolithic $\alpha_{2}\left(\mathrm{Ti}_{3} \mathrm{Al}\right)$-phase has the swirl-like antiphase domain structure and the defects of the crystalline structure (Fig. 4b).

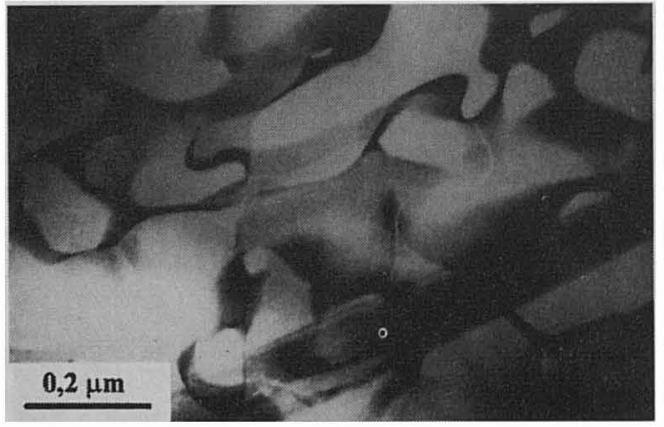

a)

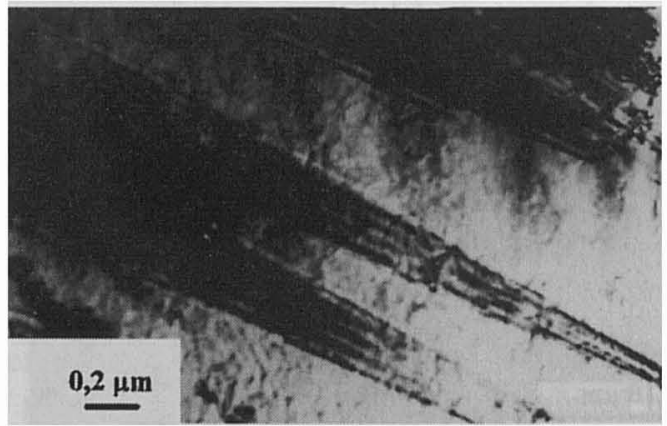

b)

Figure 4: The structure of the sample sytthesized from the TiAl-composition powder: dark-field TEM image of $\gamma-p h a s e$ (a) and bright-field image of the $\alpha_{2}-$ phase structure. 
There are some indirect proofs that the plates having the block structure and the significant lattice distortion (Fig. Sa) are attributed to the phase based on Ti-Al with the iron addition. It was observed the unusual fine lamellar structure $(\sim 50 \mathrm{~nm})$ consists of plates of two types (Fig. 5b). First ones, with fine black and white contrast, owing to the distortions, belongs to the phase originated from $\alpha_{2}$-phase and enriched with iron. The second plates, with no contrast, appertain to the $\alpha_{2}$-phase. The perlite-like structure of the regions being the wide boundaries of dendrites enriched by iron was found out.

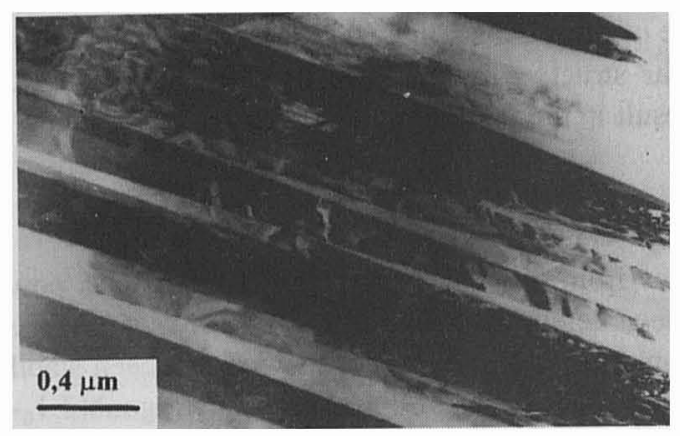

a)

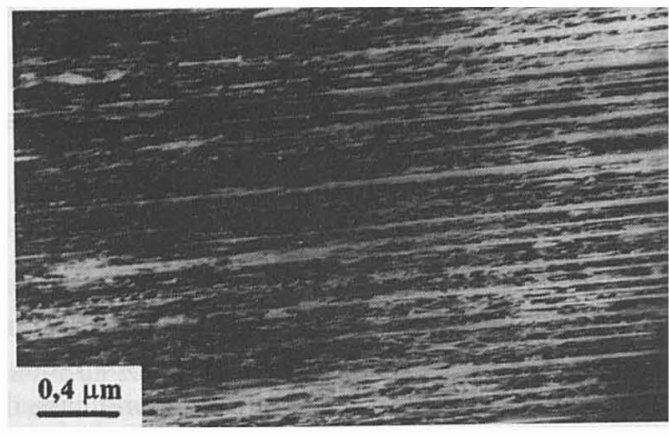

b)

Figure 5: The structure of the sample synthesized from the TiAl-composition powder: bright-fieid TEM image of the phase enriched with iron (a) and of the fine lamellar structure (b).

\subsection{Mechanism of iron penetration into the synthesized sample}

Observations of the "contamination" of powder samples, subjected to shock-wave compression, with the material of the capsule walls was informed [9-11]. We have also observed this phenomenon. However, we believe that the late plays the definite role in the formation of the sample structure and the properties.

The clear intermediate unreacted layer of the variable thickness of $50-250 \mu \mathrm{m}$ for the $\mathrm{Ti}_{3} \mathrm{Al}_{\text {sample }}$ and $\approx 500-600 \mu \mathrm{m}$ for the TiAl sample is observed between the steel shell and the synthesized sample by SEM. The microanalysis has revealed the absence of iron in the intermediate layer and its presence in the substantial amount inside the synthesized sample. This makes possible to suggest that during the shock action the iron particles injected from the steel shell into the samples with certain velocity or energy (the minimum free path is approximately equal to the intermediate layer thickness in the given case) and produce there the corresponding changes in the structure. The fact that $\mathrm{Fe}$ atoms are completely absent in the intermediate layer substantiates just the shown mechanism of the iron penetration into the sample but not the melting of the steel shell and not the diffusion of $\mathrm{Fe}$ atoms into the synthesized sample.

\subsection{Microhardness}

Measurements of microhardness of samples synthesized from $\mathrm{Ti}_{3} \mathrm{Al}$ - and $\mathrm{TiAl}$-composition powders by the method of the shock-wave compression of powder have shown that their microhardness has been considerably higher than in the case of the same samples but in the monocrystalline state (see Table).

Table. Average values of microhardness from 10 indentations, MPa.

\begin{tabular}{cccc}
\hline Sample & Middle of a radius & Center of a sample & Intermediate layer \\
\hline $\mathrm{Ti}_{3} \mathrm{Al}$ & 4774.0 & 4492.1 & $1929.0-4552.0$ \\
$\mathrm{TiAl}$ & 4188.7 & 4086.9 & $2078.0-4274.0$ \\
\hline
\end{tabular}

Microhardness of $\mathrm{Ti}_{3} \mathrm{Al}-2190.7 \mathrm{MPa}$.

According to $\left[4.5 \mid\right.$ the hardness of the $\mathrm{Ti}_{3} \mathrm{Al}$ and $\mathrm{Ti} \mathrm{Al}$ intermetallics, being quenched by usual methods as well as being annealed at temperatures in the range from 773 to $1073 \mathrm{~K}$. is within the limits 
from 1000 to $2700 \mathrm{MPa}$. These materials are "mild" when they have stoichiometric composition. Hardness increases with the formation of solid solution, i.e. at the deviation from stoichiometry and in two-phase states $\alpha+\alpha_{2}$ and $\alpha_{2}+\gamma$.

Therefore, two-phase and three-phase states of the samples synthesized in the present investigation can be considered as one of the reasons of their microhardness increase. The deviation from stoichiometry which arises owing to the formation of two- and three-phase states is apparently the second reason. The presence of the nonequilibrium phases can also play some role. One more reason for increasing microhardness can be relatively fine grains in the case of the TiAl sample (the sizes of the greater part of dendrites are equal to $2-3 \mu \mathrm{m}$ ) and the fine-lamellar structure in the case of the $\mathrm{Ti}_{3} \mathrm{Al}$ sample. All structures revealed by TEM in the both samples can result in the microhardness rise.

\section{CONCLUSIONS}

Thus, by means of the shock-wave action the samples from the $\mathrm{Ti}_{3} \mathrm{Al}$ - and TiAl-composition powders have been synthesized. Their phase composition has been determined. In the first case it was the phase of $\mathrm{Ti}_{3} \mathrm{Al}$ composition and the highly dispersed b.c.c. B2-phase in a small amount which has been stabilized due to the availability of iron. In the second case this was the mixture of three phases: tetragonal $\mathrm{L} \mathrm{1}_{0}$-type ordered $\gamma$-phase with the low long-range order parameter, slightly ordered hexagonal phase $\mathrm{Ti}_{3} \mathrm{Al}$ and nonidentified phase being, possibly, enriched with iron.

The influence of iron penetrating from the capsule of conservation on the formation of the microstructure intermetallics has been revealed. In the case of $\mathrm{Ti}_{3} \mathrm{Al}$ iron plays the role of $\beta$-stabilizer, in the case of TiAl it stimulates the growth of dendrites and is gathered along the wide dendrite boundaries in the amount of $5-10 \%$.

It has been shown that the microhardness of the synthesized intermetallics exceeds considerably the hardness values of monocrystalline samples and ones obtained by the usual methods, but approximates to the hardness of the samples prepared by the hammer-anvil quenching technique with the cooling rate of $\approx 10^{6} \mathrm{~K} / \mathrm{s}[6]$.

\section{Acknowledgments}

The authors are grateful to the Russian Fundamental Research Foundation (grant No. 95-02-05656a) for the financial support.

\section{References}

[1] Grady D., Alloy Phase Diagrams (North-Holland, New York,1982) pp. 249-252.

[2] Nesterenko V.F., Impulse Loading of Heterogeneous Materials (Nauka (Siberian Branch), Novosibirsk, 1992).

[3] Kochsiek D., Prumer R., Brunold A., Metall. 49 (1995) 168-172.

[4] Kornilov I.I., Titanium. (Nauka, Moscow, 1964) pp. 178-197.

[5] Moltchanova E.K., Diagrams of Titanium Alloys (Mashinostroenie, Moscow, 1964) pp. 185-193.

[6] Vujic D., Li L., Whang S.H., Metal. Trans. 19a (1988) 2445-2455.

[7] Chalmers B., Principles of Solidification (John Wiley \& Sons Inc., New York, 1965).

[8] Rui X., Dong L., Yuyou C., Daming X., Qingchun L., Zhuangqi H. Scr. Met. Mater. 32 (1995) 305308.

[9] Adadurov G.A., Breusov O.N., Dremin A.N., Lazarev A.I., Rus. J. Phys. Combus. Explos. 4 (1966) $130-135$.

[10] Batsanov S.S., Derbenev S.S., Deribas A.A., Dulepov E.V., Kostireva I.V., Nigmatulina V.M., Yudelevich I.G., Rus. J. Phys. Combus. Explos. 3 (1966) 110-119.

[11] Dremin A.N., Breusov O.N., Rus. J. Chem. Succes. 37 (1968) 898-916. 